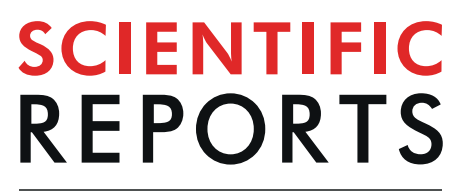

natureresearch

\title{
Carbon Monoxide Oxidation Promoted by Surface Polarization Charges in a CuO/Ag Hybrid Catalyst
}

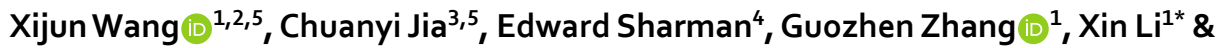 \\ Jun Jiang $\mathbb{D}^{1}$
}

Composite structures have been widely utilized to improve material performance. Here we report a semiconductor-metal hybrid structure ( $\mathrm{CuO} / \mathrm{Ag}$ ) for $\mathrm{CO}$ oxidation that possesses very promising activity. Our first-principles calculations demonstrate that the significant improvement in this system's catalytic performance mainly comes from the polarized charge injection that results from the Schottky barrier formed at the CuO/Ag interface due to the work function differential there. Moreover, we propose a synergistic mechanism underlying the recovery process of this catalyst, which could significantly promote the recovery of oxygen vacancy created via the $M-v K$ mechanism. These findings provide a new strategy for designing high performance heterogeneous catalysts.

Heterogeneous catalysts of various reactions such as $\mathrm{CO}$ oxidation have attracted widespread attention due to their high efficiency, benign environmental impact, and durability ${ }^{1-3}$. Their high catalytic activity is normally ascribed to the characteristically high charge transfer efficiency between adsorbed gas molecules and the catalyst surface, a quality which is highly dependent on the surface charge density of active sites ${ }^{4,5}$. However, precise control of charge location at the atomic level still remains a challenge ${ }^{6}$. Although tremendous attempts have been made, using methods such as shape-controlling ${ }^{7}$, chemical doping ${ }^{8}$, crystal-plane-controlling ${ }^{9}$, use of an external electric field ${ }^{10}$, etc., it still remains a considerable challenge to precisely tailor the surface charge state of these solid materials so as to enhance both activity and stability simultaneously ${ }^{11,12}$. The fundamental problem is the limited understanding of the nature of surface polarization, a barrier which seriously hinders the further practical application of heterogeneous catalysts.

To acquire deeper insight into surface polarization, recently we designed a novel semiconductor-metal interfacial structure $(\mathrm{CuO} / \mathrm{Ag})$ for $\mathrm{CO}$ oxidation ${ }^{13}$. As shown in Fig. 1, a $\mathrm{Cu}_{2} \mathrm{O}(111)$ surface was first deposited on a flat $\mathrm{Ag}(111)$ substrate, tailored to expose a $\mathrm{Cu}_{2} \mathrm{O}(100)$ surface. Following this first treatment cycle, the exposed $\mathrm{Cu}_{2} \mathrm{O}(100)$ surface was then oxidized to form a layer of $\mathrm{CuO}(100)$ surface. Compared with previous reported $\mathrm{CuO}$ based catalysts ${ }^{14-18}$, our design achieves complete conversion of $\mathrm{CO}$ at relatively low temperature $\left(150{ }^{\circ} \mathrm{C}\right)$, which performs better than bare $\mathrm{CuO} / \mathrm{Cu}_{2} \mathrm{O}^{14}$ or $\mathrm{CuO}^{15}$ (Table 1). Despite the existence of better performing materials ${ }^{16-18}$, our design can still serve as a sample model to study the promotion of charge polarization on catalytic activity. Since the thickness of $\mathrm{CuO}$ layer is $>10 \mathrm{~nm}$, we only use the $\mathrm{CuO} / \mathrm{Ag}$ model in our DFT simulations due to the limitation of computational resources. It should be noted that such $\mathrm{CuO}(100)$ layers have the same lattice constant with $\mathrm{Cu}_{2} \mathrm{O}$ surface $(\mathrm{a}=\mathrm{b}=4.27 \AA)$, which is different from normal CuO according to previous reports ${ }^{14}$. Such a unique structure may induce an interfacial polarized charge which would then penetrate the $\mathrm{CuO}(100)$ surface owing to the very thin atomic thickness along the interfacial line. Our previous results

\footnotetext{
${ }^{1}$ Hefei National Laboratory for Physical Sciences at the Microscale, CAS Key Laboratory of Mechanical Behavior and Design of Materials, School of Chemistry and Materials Science, University of Science and Technology of China, Hefei, Anhui, 230026, P.R. China. ${ }^{2}$ Department of Chemical and Biomolecular Engineering, North Carolina State University, Raleigh, North Carolina, 27606, USA. ${ }^{3}$ Guizhou Provincial Key Laboratory of Computational NanoMaterial Science, Institute of Applied Physics, Guiyang, 550018, China. ${ }^{4}$ Department of Neurology, University of California, Irvine, California, 92697, USA. ${ }^{5}$ These authors contributed equally: Xijun Wang and Chuanyi Jia. *email: lix212@ustc.edu.cn
} 


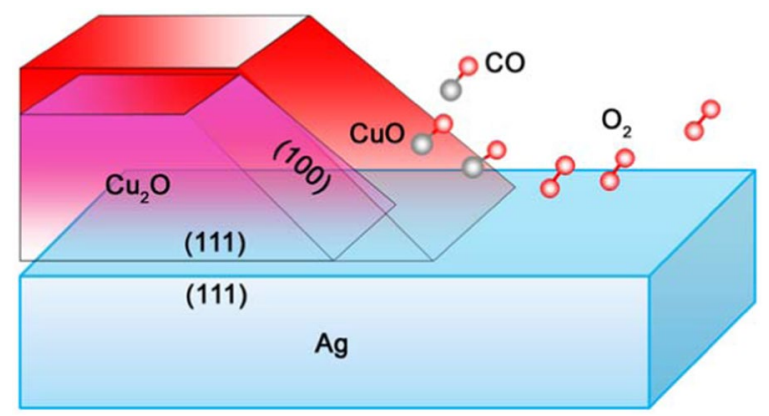

Figure 1. Schematic illustration of the $\mathrm{CuO} / \mathrm{Ag}$ hybrid structure (supported on $\mathrm{Cu}_{2} \mathrm{O} / \mathrm{Ag}$ ).

\begin{tabular}{|c|c|c|}
\hline & \begin{tabular}{|l|}
$\begin{array}{l}\text { CO Conversion } \\
(\%)\end{array}$ \\
\end{tabular} & \begin{tabular}{|l|} 
Reaction \\
Temperature $\left({ }^{\circ} \mathrm{C}\right)$ \\
\end{tabular} \\
\hline $\mathrm{Ag} / \mathrm{CuO}\left(\right.$ ref. $\left.^{13}\right)$ & 100.0 & 150 \\
\hline $\mathrm{CuO} / o-\mathrm{Cu}_{2} \mathrm{O}\left(\right.$ ref. $\left.{ }^{14}\right)$ & 93.2 & 240 \\
\hline $\mathrm{CuO} / c-\mathrm{Cu}_{2} \mathrm{O}\left(\right.$ ref. $\left.{ }^{14}\right)$ & 49.1 & 240 \\
\hline $\mathrm{CuO}\left(\right.$ ref. $\left.^{15}\right)$ & 22.5 & 205 \\
\hline $\mathrm{CuO} / \mathrm{CeO}_{2}$ (ref. ${ }^{16}$ ) & 99.0 & 117 \\
\hline $\mathrm{Au} / \mathrm{CuO}_{2}\left(\right.$ ref. $\left.{ }^{17}\right)$ & 32.5 & 88 \\
\hline $\mathrm{Au} / \mathrm{CuO}_{\mathrm{x}}-\mathrm{TiO}_{2}$ (ref. ${ }^{17}$ ) & 100.0 & 80 \\
\hline $\begin{array}{l}\mathrm{Au} / \mathrm{CuO}_{2} \text { in } \mathrm{O}_{\text {- }} \text {-rich } \\
\text { stream (ref. }{ }^{18} \text { ) }\end{array}$ & 100.0 & 55 \\
\hline
\end{tabular}

Table 1. CO conversion and reaction temperatures of different $\mathrm{CuO}$ based catalysts.

demonstrated that this polarized charge along the interfacial line enables controllable highly efficient CO oxidation with good durability. By maximizing the $\mathrm{Ag} / \mathrm{CuO}$ interfacial length, the $\mathrm{CO}$ conversion rate can be linearly enhanced.

However, there are still several unsolved problems requiring clarification, such as elucidating the formation process of interfacial polarization, the mechanism of transfer of polarized charge at the interface, and how polarized charge impacts catalyst activity. To gain deeper insight into these inner mechanisms, we now extend our study of this system, so as to provide more confidence and experience in designing new composite functional materials.

\section{Computational Methods}

All the calculations were performed at the spin-polarized density functional (DFT) level of theory as implemented in the Vienna ab initio Simulation package (VASP) ${ }^{19}$. The frozen-core all-electron projector augmented wave (PAW) model ${ }^{20}$ with Perdew-Burke-Ernzerhof (PBE) functionals ${ }^{21}$ was employed to describe the interactions between core and electrons. An energy cutoff of $450 \mathrm{eV}$ was used for the plane-wave expansion of the electronic wave function. The force convergence criterion was set to $0.01 \mathrm{eV} / \AA$ for pure $\mathrm{Ag}$ and $\mathrm{Cu}_{2} \mathrm{O} / \mathrm{CuO}$ unit structures and $0.05 \mathrm{eV} / \AA$ for the composite $\mathrm{CuO} / \mathrm{Ag}$ model, respectively. The energy convergence criterion was set to $10^{-5} \mathrm{eV}$. A k-point grid with a $7 \times 7 \times 1$ Monkhorst-Pack mesh for pure $\mathrm{Cu}_{2} \mathrm{O} / \mathrm{CuO}$ and $\mathrm{Ag}(100)$ and (111) facets was chosen for sampling the Brillouin zone, while for the $\mathrm{CuO} / \mathrm{Ag}$ structure, due to the huge size of the model, only Gamma point was performed. A Bader analysis of charge density of atoms was used to analyze the charge distribution ${ }^{22}$, and the nudged elastic band (NEB) method ${ }^{23}$ was employed to search the transition states of elementary steps during the $\mathrm{CO}$ oxidation reaction.

The $\mathrm{Cu}_{2} \mathrm{O} / \mathrm{CuO}(100) 6 \times 3$ supercell structure (the $\mathrm{CuO}$ surface was evolved from the $\mathrm{Cu}_{2} \mathrm{O}(100)$ surface) in Fig. 2a consists of 9 layers of $\mathrm{Cu}_{2} \mathrm{O}(100), 12$ layers of $\mathrm{CuO}$, and 4 transition layers in between ${ }^{14}$, with the

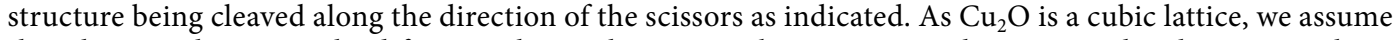
that the $\mathrm{CuO}$ lattice evolved from it shares the same cubic geometry, thus we set the cleavage angle to $35.26^{\circ}\left(\tan ^{-1} \sqrt{2}\right)$ to ensure that the newly formed surface is a $\mathrm{CuO}(111)$ facet. A 4 layer Ag cluster derived from a pure $\mathrm{Ag}(111)$ surface model was used to simulate the silver substrate. Then we combined the cleaved $\mathrm{Cu}_{2} \mathrm{O} / \mathrm{CuO}$ supercell and the Ag cluster together to mimic the $\mathrm{CuO} / \mathrm{Ag}$ composite structure. As shown in Fig. 2b, such a unique interfacial configuration only has periodicity in the y-direction with a lattice constant of $12.81 \AA$, while in the $\mathrm{x}$ and $\mathrm{z}$ directions we add $\sim 15 \AA$ vacuum layers to avoid artificial interactions between slabs. It is noteworthy that the experimentally-determined thickness of the $\mathrm{CuO}$ shell is approximately 6 to $10 \mathrm{~nm}^{14}$, indicating that the $\mathrm{CuO}(111)$ and (100) surfaces are minimally influenced by $\mathrm{Cu}_{2} \mathrm{O}$. Therefore our final simplified $\mathrm{CuO} / \mathrm{Ag}$ model does not contain $\mathrm{Cu}_{2} \mathrm{O}$. During relaxation all the atoms were relaxed except for the bottom 2 layers. 

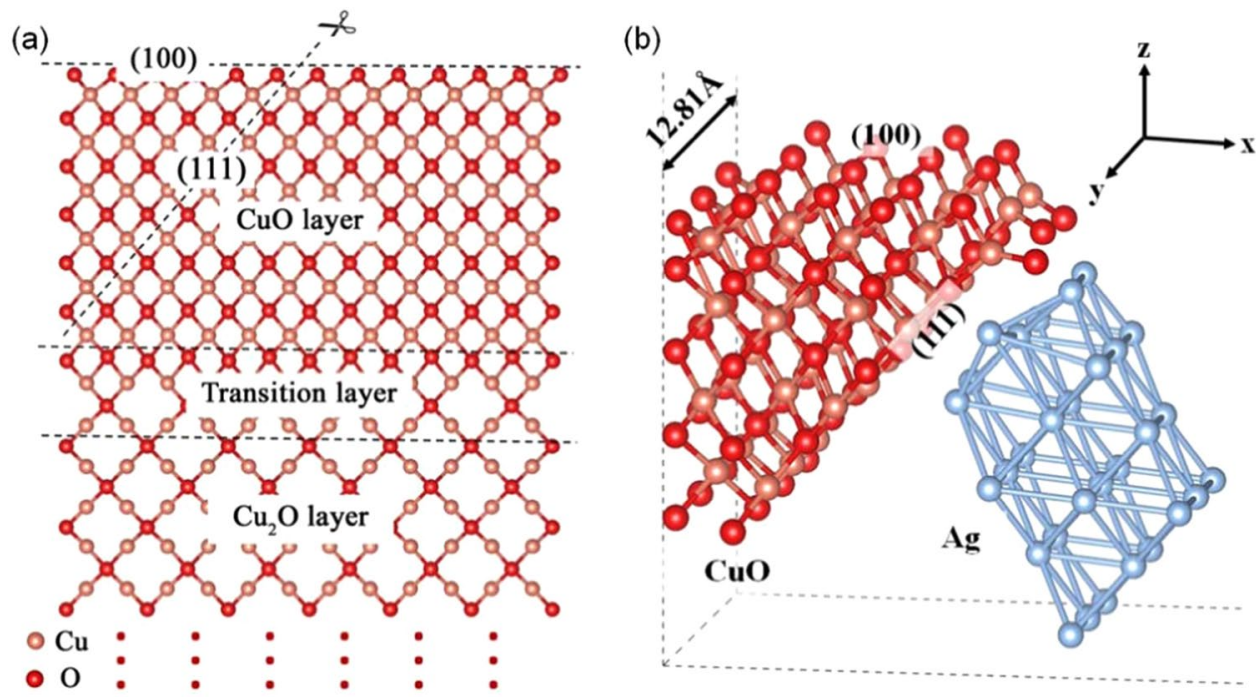

Figure 2. Construction of $\mathrm{CuO}^{*}$ model and the $\mathrm{CuO} / \mathrm{Ag}$ interface. (a) Structural model of the $\mathrm{CuO} / \mathrm{Cu}_{2} \mathrm{O}(100)$ interface. (b) Structural model of the $\mathrm{CuO}(111) / \mathrm{Ag}(111)$ interface.
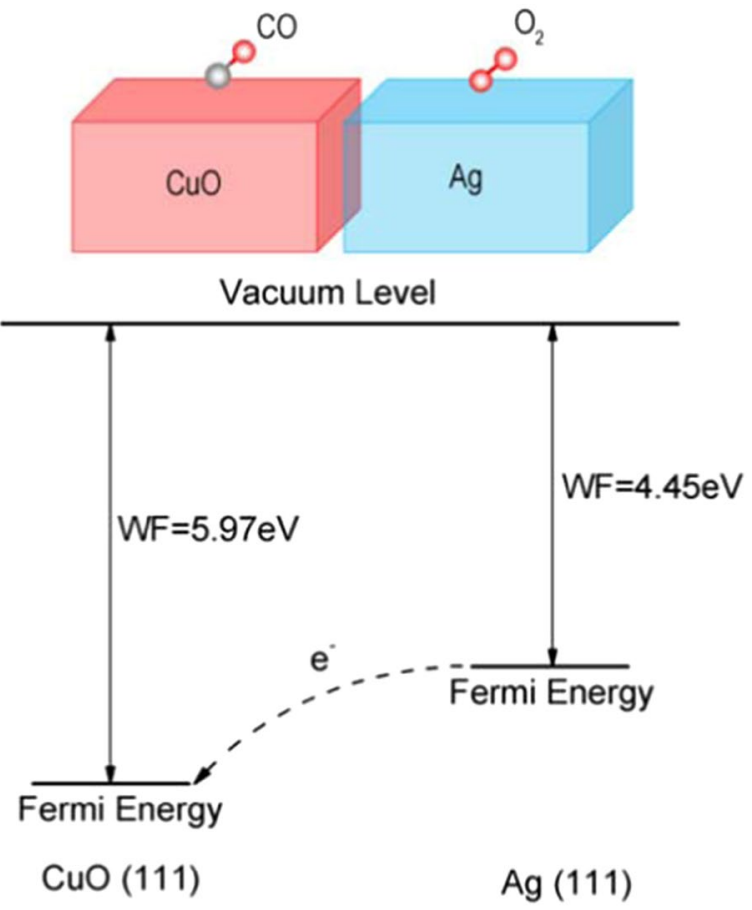

Figure 3. Diagram of the mechanism of charge transfer induced by the difference in work functions between the $\mathrm{CuO}(111)$ and $\mathrm{Ag}(111)$ surfaces.

\section{Results and Discussion}

Formation of the interfacial charge polarization. According to the Schottky-Mott rule ${ }^{24}$, a Schottky barrier should be formed at the metal-semiconductor junction due to the difference in work function between the two materials ${ }^{25}$. In our case, because the work functions of $\mathrm{Ag}(111)$ and $\mathrm{CuO}(111)$ differ, surface polarization is inevitably induced at the $\mathrm{CuO} / \mathrm{Ag}$ interface, as shown in Fig. 3. The work function of $\mathrm{CuO}(111)(5.97 \mathrm{eV})$ is much higher than that of the $\mathrm{Ag}(111)$ substrate $(4.45 \mathrm{eV})$, indicating that the Fermi level of pure $\mathrm{CuO}$ is much lower than that of pure Ag. As a consequence, after the combination of these two materials, electrons should transfer from the one with a higher potential level to the material with a lower one, that is from $\operatorname{Ag}(111)$ to $\mathrm{CuO}(111)$ through the interface, thus generating electron-hole pairs. The effective separation of electrons and holes is usually referred to as interfacial polarization.

Such a charge polarization is shown in Fig. 4a. Electrons should transfer from $\mathrm{Ag}$ (cyan colour) to $\mathrm{CuO}$ (olive colour) owing to the interfacial polarization effect driven by the work function difference at the interface. The 
(a)

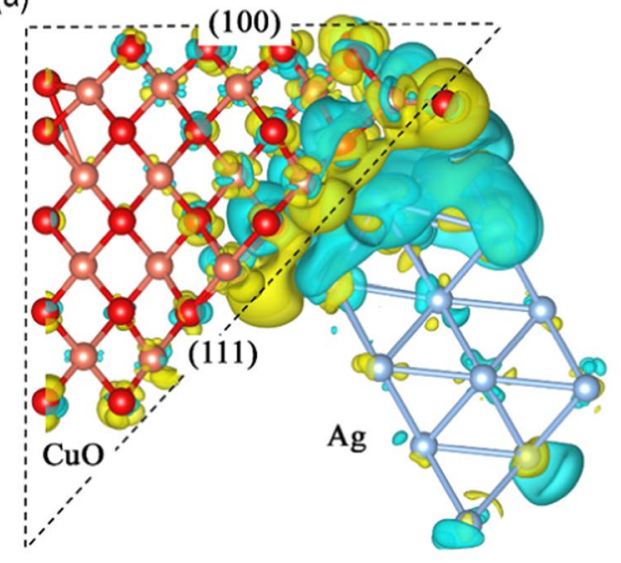

(b)

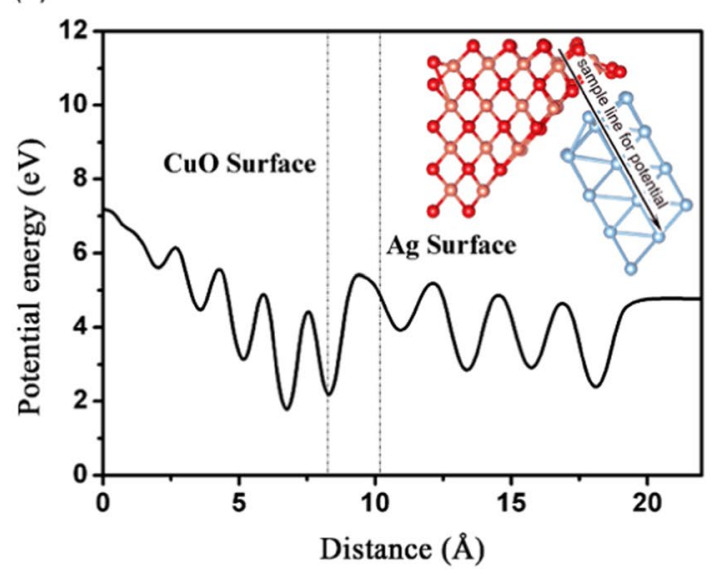

Figure 4. Charge transfer at the $\mathrm{CuO} / \mathrm{Ag}$ interface. (a) Computed spatial distributions of charge density differences at the $\mathrm{CuO}(111) / \mathrm{Ag}(111)$ interface. Here olive and cyan colors represent an increase (olive color) or a decrease (cyan color) in the electronic charge distribution. (b) Variations in static potential along the line traversing the $\mathrm{Ag}(111) / \mathrm{CuO}$ interface, in the direction of the arrow.

number of transferred electrons is calculated by Bader charge analysis to be $2.29 \mathrm{e}^{-}$. To further elucidate the electrostatic potential difference at the interface, the static potential surface along the direction perpendicular to the interface is given in Fig. 4b. Obviously the potential energy of Ag is higher than that of CuO along the sampling line, indicating the direction of the Schottky junction so formed. Through this junction, electrons can easily transfer from $\mathrm{Ag}$ to $\mathrm{CuO}$ but return again only with difficulty; by this means effective charge separation and charge polarization at the interface is achieved. It is worth mentioning that due to the limitation of computing power, we only use the small $\mathrm{Ag}$ cluster model derived from $\mathrm{Ag}(111)$ surface in this work. To ensure the validity of the charge transfer trend, we also performed a test calculation by using a 3-layers $\mathrm{Ag}(111)$ surface model as the substrate (Fig. S1). Results show a consistent trend that electrons still transfer from Ag to CuO even at large $\mathrm{Ag}(111)$ substrate. It should be noted that the conclusions made in this work are based on the interactions between $\mathrm{O}_{2}$ molecule and clean unoxidized $\mathrm{Ag}$ surface. The real $\mathrm{O}_{2} / \mathrm{Ag}$ interactions could be far more complicated due to the formation of the epitaxial $\mathrm{Ag}_{2} \mathrm{O}$ thin oxide overlayers on the surface of $\mathrm{Ag}^{26}$, which could affect the overall catalytic activities. To estimate its impact, we artificially added an $\mathrm{Ag}_{3} \mathrm{O}$ cluster to mimic the $\mathrm{Ag}_{2} \mathrm{O}$ layer in the middle between $\mathrm{CuO}$ and $\mathrm{Ag}$ as shown in Fig. S2. Results show that although the direction of charge transfer keeps unchanged, the transferred Bader charge decreases from 2.29 to $1.32 \mathrm{e}^{-}$, indicating that the oxidation layer could reduce the catalytic activity to some extent. Therefore, we strongly suggest that the surface oxidation layer of Ag should be removed first when preparing the $\mathrm{CuO} / \mathrm{Ag}$ catalyst experimentally.

Charge transfer inside the CuO lattice. After the interfacial polarization forms, a new question arises: how do electrons transfer inside the $\mathrm{CuO}$ lattice? As work function is defined as the thermodynamic work required to remove an electron from a material to the vacuum near its surface, a crystal facet with a higher work function should be more likely to accumulate electrons ${ }^{25,27}$. As shown in Fig. 5a, the work function of the $\mathrm{CuO}(100)$ facet $(8.28 \mathrm{eV})$ is much higher than that of the (111) facet $(5.97 \mathrm{eV})$, indicating that electrons are more likely to accumulate on $\mathrm{CuO}(100)$. To further illustrate this point, we performed partial density of states (PDOS) calculations of isolated $\mathrm{CuO}(100)$ and (111) surface atoms (Fig. 5b). The results show that $\mathrm{CuO}(100)$ and (111) have very similar electronic structures except for a very strange "shift" - similar electronic orbitals while different orbital occupations, leading to a difference in their Fermi levels. After electron charge injection resulting from external electron donation, electrons tend to transfer from a facet with a higher Fermi level to one with a lower one, that is from $\mathrm{CuO}(111)$ to (100). Eventually, the polarized charge due to interfacial polarization accumulates on the (100) surface, a property that affects the catalytic activity of the system. It is wort mentioning that the metallic properties the surfaces are caused by the unsaturated atoms on the surface, the $\mathrm{CuO}$ and $\mathrm{Cu}_{2} \mathrm{O}$ bulk structures are semiconductors according to previous reports ${ }^{13,14}$.

Effect of charge polarization on catalytic activity. Having computed the polarized charge accumulation on the $\mathrm{CuO}(100)$ surface, we now move on to study its impact on catalytic activity. CO oxidation on the $\mathrm{CuO}$ surface follows the Mars-Van Krevelen $(\mathrm{M}-\mathrm{vK})$ mechanism ${ }^{28,29}$. The $\mathrm{CuO}(100)$ surface is terminated by two-coordinated oxygen $\left(\mathrm{O}_{2 \mathrm{c}}\right)$ atoms, which can easily combine with $\mathrm{CO}$ to form a $\mathrm{CO}_{3}$ surface intermediate. The $\mathrm{CO}_{3}$ intermediate easily decomposes to produce $\mathrm{CO}_{2}$, leaving an oxygen vacancy (Vo) at the active site. In order to evaluate the role of $\mathrm{Ag}$ in the $\mathrm{CO}$ oxidation, we built a new model $\mathrm{CuO} *$ by intentionally removing the Ag substrate from the $\mathrm{CuO} / \mathrm{Ag}$ model as shown in Fig. 6a. Transition state search results (Fig. 6) reveal that the polarization charge accumulation induced by the Ag substrate dramatically lowers the barrier of CO oxidation from $0.60 \mathrm{eV}$ to $0.24 \mathrm{eV}$. This indicates that interfacial polarization indeed enhances catalytic activity. Since it is suggested that the removal of the surface lattice oxygen is the rate-determining step of CO oxidation for the M-vK mechanism ${ }^{13,28,29}$, we compared our result $(0.24 \mathrm{eV})$ with the barriers of rate-determining steps in other 
(a)

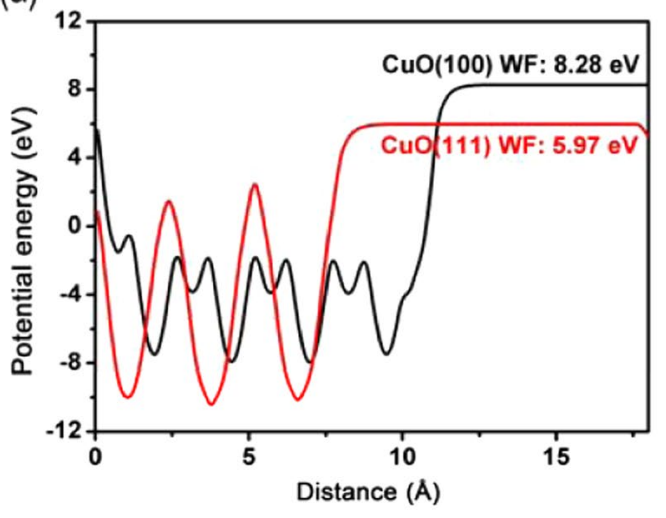

(b)

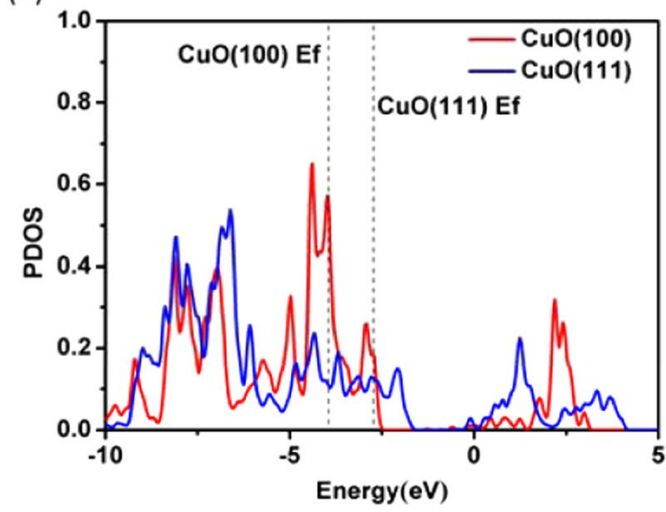

Figure 5. WF and PDOS of $\mathrm{CuO}(100)$ and (111) facets. (a) Computed potential energy of $\mathrm{CuO}(100)$ and (111) facets along $\mathrm{z}$-axis direction. The Fermi level is alighed at zero. Work functions are the convergent values of these curves. (b) Computed partial density of states of isolated $\mathrm{CuO}(100)$ and (111) surface atoms.

(a)

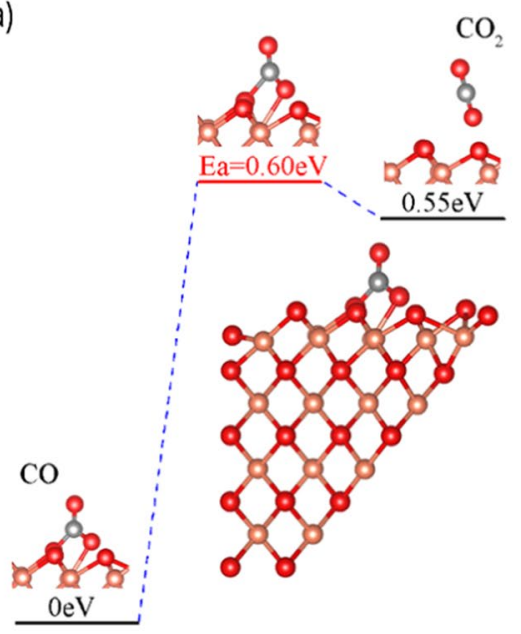

(b)

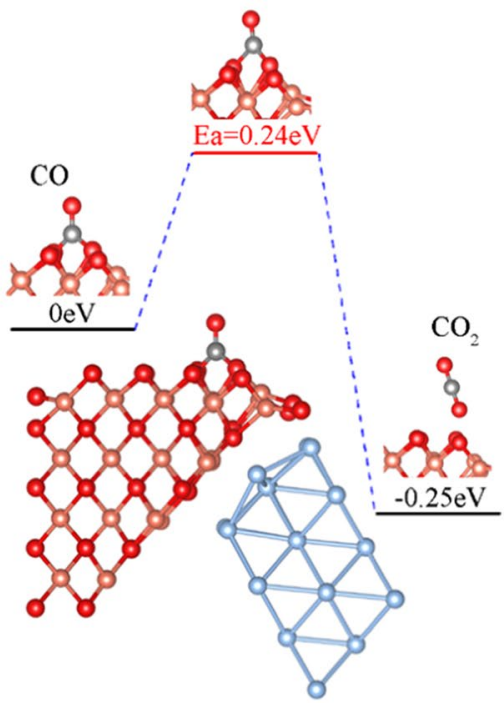

Figure 6. Minimum energy path for $\mathrm{CO}$ oxidation on $\mathrm{CuO}(100)$ surface in the (a) $\mathrm{CuO}^{*}$ and $(\mathbf{b}) \mathrm{CuO} / \mathrm{Ag}$ systems.

relevant systems, such as $\mathrm{CO}$ oxidation on $\mathrm{Cu}_{2} \mathrm{O}(111)(1.63 \mathrm{eV})^{30}, \mathrm{CuO} / \mathrm{Cu}_{2} \mathrm{O}(110)(0.60 \mathrm{eV})^{31}, \mathrm{CuO} / \mathrm{Cu}_{2} \mathrm{O}(100)$ $(1.15 \mathrm{eV})^{14}$, and $\mathrm{CuO} / \mathrm{Cu}_{2} \mathrm{O}(111)(0.37 \mathrm{eV})^{14}$, illustrating the superiority of our $\mathrm{CuO} / \mathrm{Ag}$ model.

To further understand the enhancement of catalytic activity, we then calculated the $\mathrm{CO}$ adsorption energy on a $\mathrm{CuO}(100)$ surface in both the $\mathrm{CuO}^{*}$ and $\mathrm{CuO} / \mathrm{Ag}$ models. Normally, optimum activity is obtained at an intermediate adsorption energy according to the volcano shape rule $^{32,33}$. Our results show that the $\mathrm{CO}$ adsorption energy in the $\mathrm{CuO}^{*}$ system is $3.19 \mathrm{eV}$ while in $\mathrm{CuO} / \mathrm{Ag}$ it is $2.94 \mathrm{eV}$, indicating that the polarized charge drags the adsorption energy down closer to an optimum value, thereby enhancing catalytic activity.

In addition, the effect of polarization charge on the lattice oxygen reactivity of $\mathrm{CuO}(100)$ was also carefully studied. In the presence of the Ag substrate, the activation energy of a lattice oxygen decreases from $5.34 \mathrm{eV}$ to $5.11 \mathrm{eV}$ (Fig. S3), and the energy required to form an oxygen vacancy decreases from $5.68 \mathrm{eV}$ to $5.36 \mathrm{eV}$. These changes in energy indicate that the injection of polarized charge can significantly assist activating lattice oxygen atoms, suggesting better catalytic activity.

Effect of charge polarization on $V_{O}$ recovery. After $\mathrm{CO}$ oxidation, the refilling of $V_{O}$ is vital in order to enable the next reaction cycle. Our adsorption energy calculations (Table 2) indicate that in the presence of the Ag substrate, the $\mathrm{O}_{2}$ adsorption energy at the oxygen vacancy site on the $\mathrm{CuO}(111)$ surface increases from $1.45 \mathrm{eV}$ to $1.64 \mathrm{eV}$, which should result in a significant improvement in catalytic recovery. $\mathrm{CO}$ cannot compete with $\mathrm{O}_{2}$ during the recovery process due to its much lower adsorption energy. Also, because $\mathrm{O}_{2}$ adsorption on $\mathrm{Ag}$ is weak, $\mathrm{O}_{2}$ prefers adsorption at the $V_{O}$ site and thus readily heals the defect there. Such a feature agrees well with our previous experimental work $^{13}$. 


\begin{tabular}{|l|l|l|l|l|l|l|}
\hline Species & $\mathbf{C u O} *(\mathbf{V o})$ & $\mathbf{C u O}(\mathbf{V o}) / \mathbf{A g}$ & $\mathbf{C u O} *$ & $\mathbf{C u O} / \mathbf{A g}$ & $\mathbf{A g}$ & $\mathbf{A g}^{+}$ \\
\hline $\operatorname{Ead}^{\mathrm{O} 2}(\mathrm{eV})$ & 1.45 & 1.64 & 0.00 & 0.01 & 0.01 & 0.28 \\
\hline $\mathrm{Ead}^{\mathrm{CO}}(\mathrm{eV}]$ & 0.96 & 1.11 & 2.80 & 2.94 & 0.12 & 0.66 \\
\hline
\end{tabular}

Table 2. Calculated $\mathrm{O}_{2}$ and $\mathrm{CO}$ adsorption energy Ead for $\mathrm{CuO}^{*}$ and $\mathrm{CuO} / \mathrm{Ag}$ with and without a surface oxygen vacancy, and for Ag with and without holes.
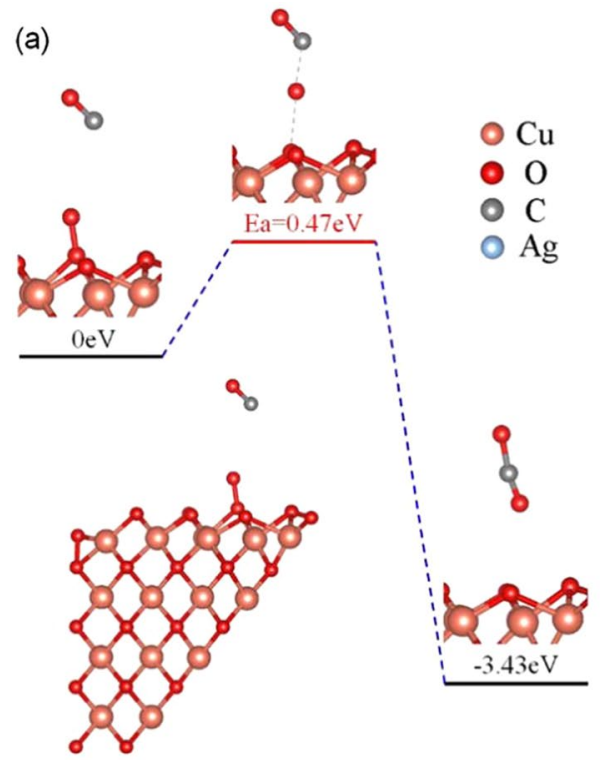

(b)

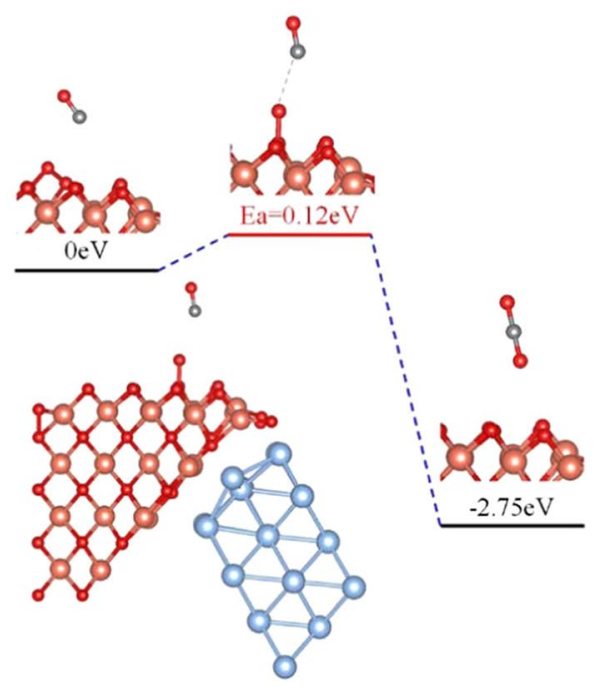

Figure 7. Minimum energy path for $\mathrm{CO}$ oxidation at the redundant oxygen site on $\mathrm{CuO}(100)$ surface in the (a) $\mathrm{CuO}^{*}$ and (b) $\mathrm{CuO} / \mathrm{Ag}$ systems.

After $\mathrm{O}_{2}$ has reoccupied the oxygen vacancy, there should be one additional oxygen atom bound to the $\mathrm{CuO}(100)$ surface. This redundant oxygen atom can be much more active than a lattice oxygen ${ }^{14}$. We calculated the desorption activation energy by removing a redundant oxygen atom gradually from the $\mathrm{CuO}(100)$ surface in both $\mathrm{CuO}^{*}$ and $\mathrm{CuO} / \mathrm{Ag}$ models as shown in Fig. S4. The resulted desorption energies are much lower than the lattice oxygen activation energies (Fig. S3), suggesting that the activation of the redundant oxygen should be much easier than the lattice oxygen. Moreover, NEB simulations further demonstrated that the reaction between $\mathrm{CO}$ and the redundant oxygen is not the rate-determine step in the reaction cycles on both $\mathrm{CuO} *$ and $\mathrm{CuO} / \mathrm{Ag}$ due to the very low barriers of 0.47 and $0.12 \mathrm{eV}$ respectively as shown in Fig. 7.

Effect of charge polarization on the Ag substrate. In addition to $\mathrm{CuO}$, we also focused on the impact of charge polarization on the $\mathrm{Ag}$ substrate. After combining $\mathrm{CuO}$ and $\mathrm{Ag}$, holes should remain on $\mathrm{Ag}(111)$ as mentioned above. Compared with neutral $\mathrm{Ag}$, $\mathrm{Ag}$ with a hole $\left(\mathrm{Ag}^{+}\right)$has stronger adsorption energies for both $\mathrm{O}_{2}$ and $\mathrm{CO}$ (Table 2), which may result from the charge redistributions. The neutral Ag donates $0.41 \mathrm{e}^{-}$electrons to $\mathrm{O}_{2}$ after adsorption while $\mathrm{Ag}^{+}$has almost no charge exchange with $\mathrm{O}_{2}$. However, $\mathrm{Ag}^{+}$can induce a significant charge redistribution on $\mathrm{O}_{2}$ compared with $\mathrm{Ag}$ as depicted in Fig. 8a,b. The electrons that originally away from $\mathrm{Ag}$ substrate would accumulate in the middle between $\mathrm{Ag}$ and $\mathrm{O}_{2}$ after $\mathrm{O}_{2}$ adsorption. These redistributed electrons thus form a strong electrostatic interaction with the positive charge on $\mathrm{Ag}^{+}$, increasing the adsorption energy from 0.01 to $0.28 \mathrm{eV}$ (Table 2). A similar phenomenon occurs in the case of CO adsorption (Fig. 8), wherein neutral Ag donates $0.09 \mathrm{e}^{-}$electrons to $\mathrm{CO}$ during adsorption while $\mathrm{Ag}^{+}$receives $0.05 \mathrm{e}^{-}$from $\mathrm{CO}$; the charge redistribution in $\mathrm{CO}$ enhances the electrostatic attraction between $\mathrm{Ag}$ and $\mathrm{CO}$, and thus increases the adsorption energy from 0.12 to $0.66 \mathrm{eV}$.

Keeping these adsorption energies in mind (Table 2), we propose a reasonable conjecture, a synergistic effect that encompasses the whole catalyst recovery process. Before $\mathrm{CO}$ oxidation, $\mathrm{CO}$ tends to adsorb on the $\mathrm{CuO}$ surface, while $\mathrm{O}_{2}$ prefers to adsorb on the Ag substrate; this differential preference is due to their different adsorption energies. After the creation of $V_{O}$ site on $\mathrm{CuO}$ surface, at certain temperatures and pressures, in addition to obtaining oxygen from the air, it is also possible for $V_{O}$ sites to obtain oxygen from Ag substrate due to the short distance between $\mathrm{CuO}$ and $\mathrm{Ag}$, and the huge difference in $\mathrm{O}_{2}$ adsorption energies of these two materials. The barrier of $\mathrm{O}_{2}$ migration from $\mathrm{Ag}$ surface to $\mathrm{CuO} V_{O}$ site was studied by using the larger model in Fig. S1. Due to the limitation of the computing power, here a lower level of accuracy (cutoff energy $=300 \mathrm{eV}$ ) was applied and only the atoms that are directly bind with $\mathrm{O}_{2}$ are allowed to relax during the NEB calculations. The potential energy surface of $\mathrm{O}_{2}$ migration (Fig. 9) shows a negligible barrier of $0.02 \mathrm{eV}$, indicating that $\mathrm{O}_{2}$ migration is readily to occur at ambient conditions. Overall, the Ag substrate acts as an $\mathrm{O}_{2}$ store, which collects $\mathrm{O}_{2}$ molecules before catalytic reaction, and then delivers these to $\mathrm{CuO}$ once $V_{O}$ forms, thus facilitating $\mathrm{CuO}$ recovery. The energy profile 
(a)

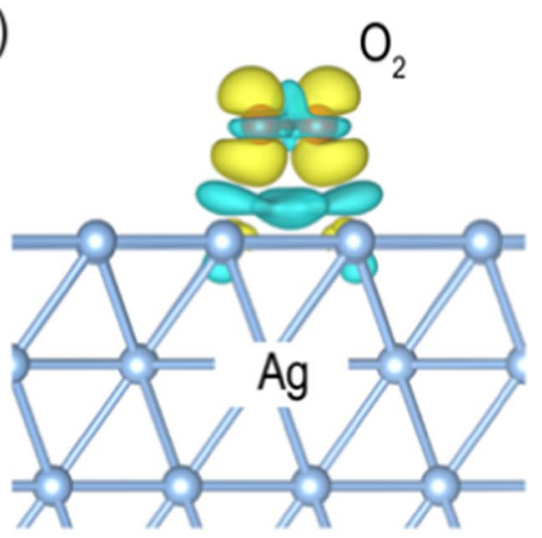

(c)

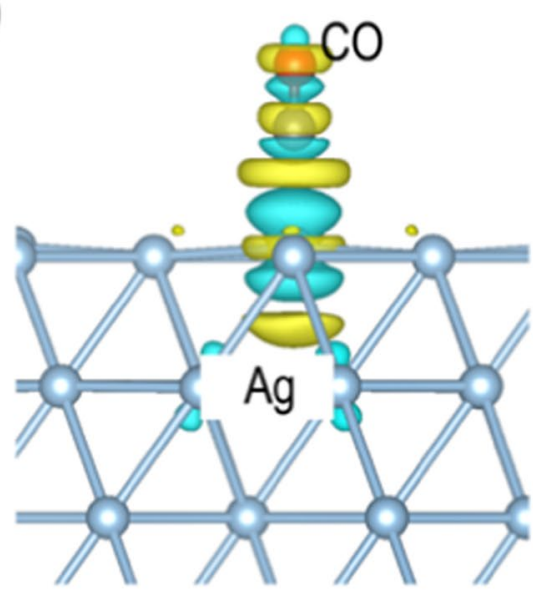

(b)
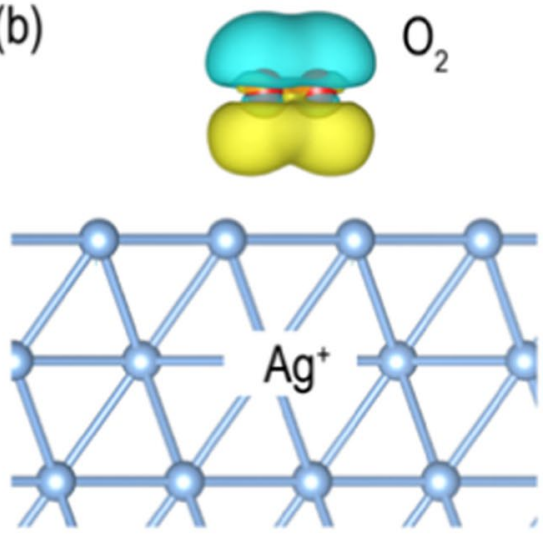

(d)

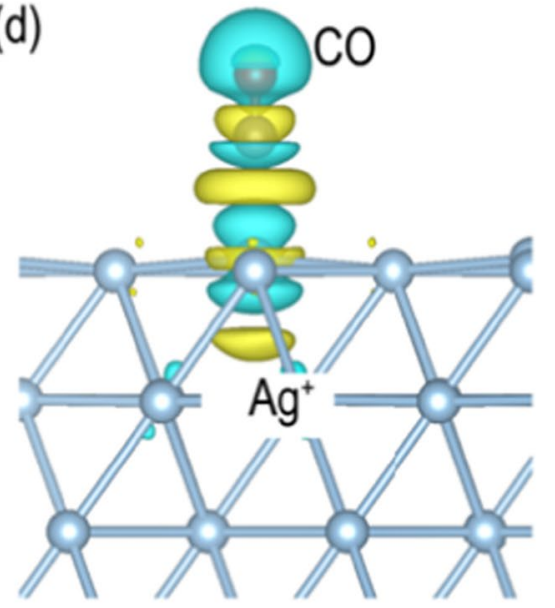

Figure 8. Differential charge densities for $\mathrm{O}_{2} / \mathrm{CO}$ adsorption on $\mathrm{Ag} / \mathrm{Ag}+$. (a) $\mathrm{O}_{2}$ adsorption on Ag; (b) $\mathrm{O}_{2}$ adsorption on $\mathrm{Ag}^{+}$; (c) $\mathrm{CO}$ adsorption on $\mathrm{Ag}$; (d) $\mathrm{CO}$ adsorption on $\mathrm{Ag}^{+}$. After adsorption, electrons transfer from the cyan areas to the olive areas.

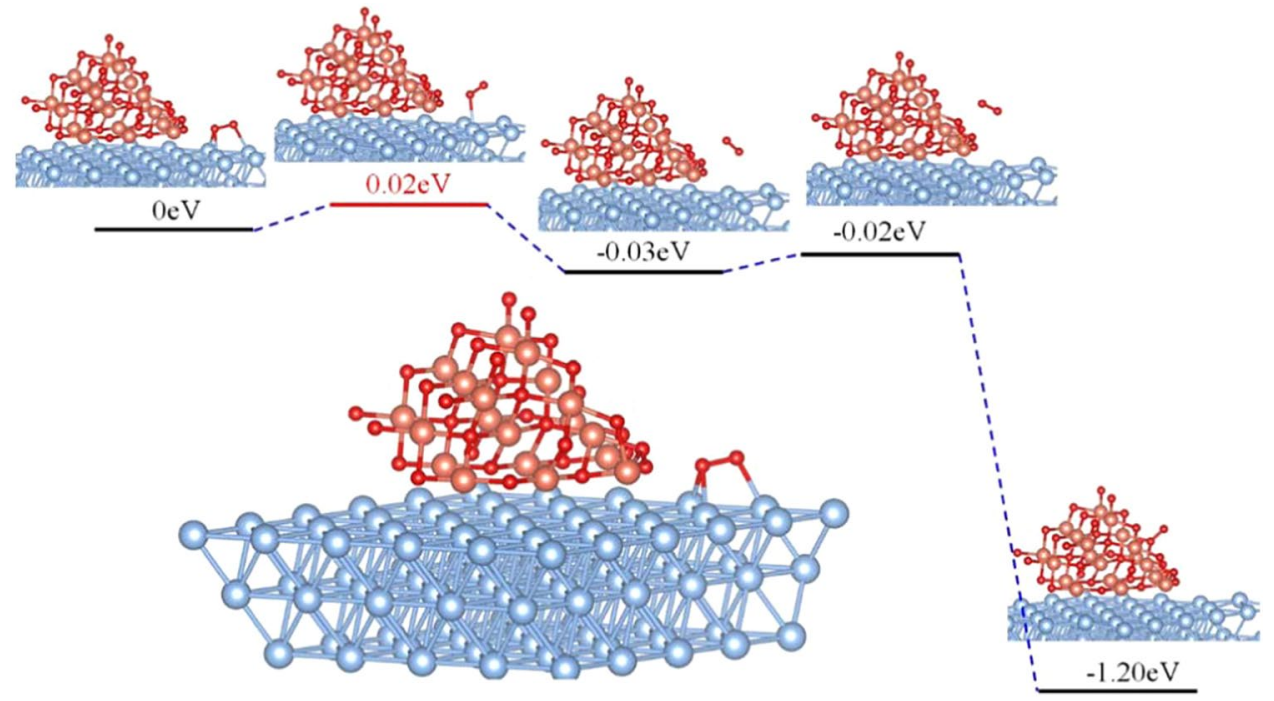

Figure 9. Minimum energy path for $\mathrm{O}_{2}$ migration from $\mathrm{Ag}(111)$ surface to the $V_{O}$ site on $\mathrm{CuO}(100)$.

of each elementary step in $\mathrm{CO}$ oxidation catalyzed by $\mathrm{CuO} *$ (blue lines) and $\mathrm{CuO} / \mathrm{Ag}$ (red lines) are summarized as shown in Fig. 10, showing that the presence of Ag substrate can not only significantly lower down the barriers of CO oxidation, but also promote the recovery of the surface $V_{O}$ site, making the catalyst more efficient. 


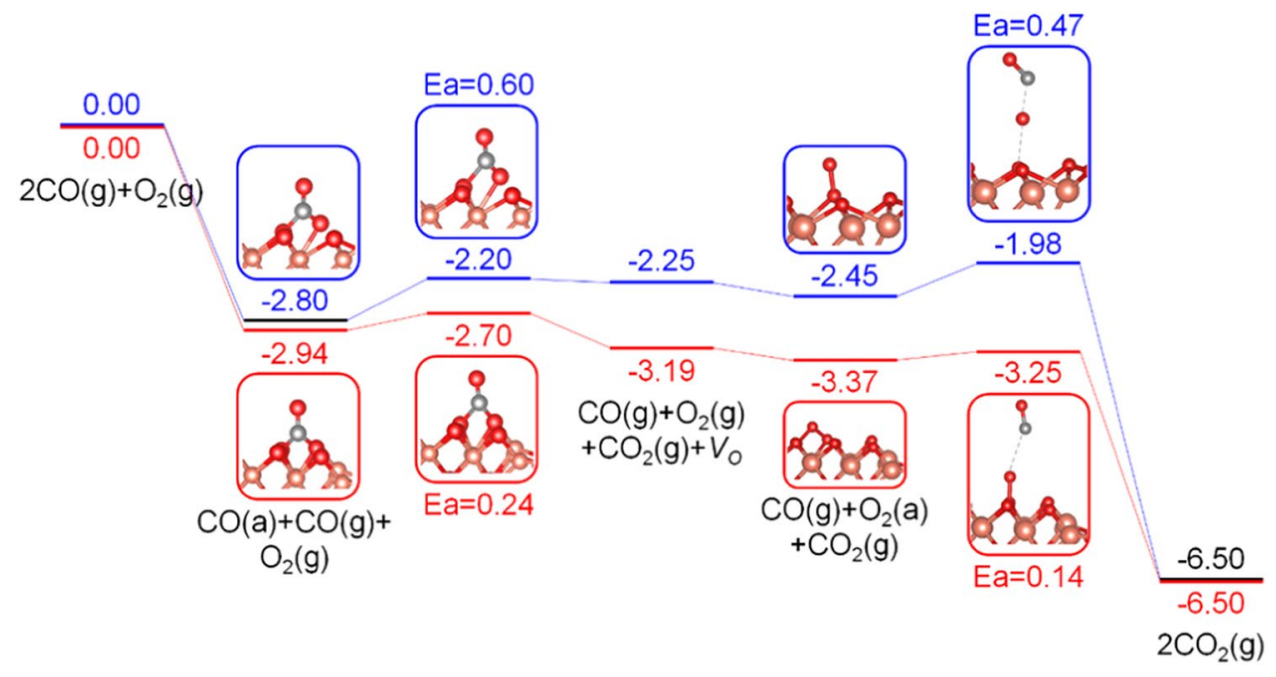

Figure 10. Energy profile of each elementary step in $\mathrm{CO}$ oxidation catalyzed by $\mathrm{CuO} *$ (blue lines) and $\mathrm{CuO} / \mathrm{Ag}$ (red lines).

\section{Conclusion}

In summary, by utilizing an interfacial polarization effect, we have designed a $\mathrm{CuO} / \mathrm{Ag}$ heterogeneous catalyst for $\mathrm{CO}$ oxidation with very promising catalytic activity. The significant improvement in catalytic performance is ascribed to the accumulation of polarization charge on the $\mathrm{CuO}$ surface that is induced by the work function difference between $\mathrm{CuO}$ and $\mathrm{Ag}$. Interestingly, charge polarization can not only promote $\mathrm{CO}$ oxidation, but also promote the healing of the $V_{O}$ defect, making the catalyst more durable. These new insights from the case of $\mathrm{CuO} /$ Ag can be helpful for studying how the polarization effect may improve other catalytic systems, providing a new approach toward the rational design of more efficient heterogeneous catalysts.

Received: 29 January 2019; Accepted: 28 January 2020;

Published online: 13 February 2020

\section{References}

1. Li, C. et al. Shape-Controlled $\mathrm{CeO}_{2}$ Nanoparticles: Stability and Activity in the Catalyzed HCl Oxidation Reaction. ACS Catalysis 7 , 6453-6463 (2017).

2. Rodriguez, J. A., Grinter, D. C., Liu, Z., Palomino, R. M. \& Senanayake, S. D. Ceria-based model catalysts: fundamental studies on the importance of the metal-ceria interface in $\mathrm{CO}$ oxidation, the water-gas shift, $\mathrm{CO}_{2}$ hydrogenation, and methane and alcohol reforming. Chem. Soc. Rev. 46, 1824-1841 (2017).

3. Jia, C. et al. Catalytic Chemistry Predicted by a Charge Polarization Descriptor: Synergistic $\mathrm{O}_{2}$ Activation and CO Oxidation by $\mathrm{Au}-\mathrm{Cu}$ Bimetallic Clusters on $\mathrm{TiO}_{2}$ (101). ACS Appl. Mater. Inter. 11, 9629-9640.

4. Hellman, A., Klacar, S. \& Grönbeck, H. Low Temperature CO Oxidation over Supported Ultrathin MgO Films. J. Am. Chem. Soc. 131, 16636-16637 (2009).

5. Xing, L. et al. Realizing room-temperature self-powered ethanol sensing of $\mathrm{Au} / \mathrm{ZnO}$ nanowire arrays by coupling the piezotronics effect of $\mathrm{ZnO}$ and the catalysis of noble metal. Appl. Phys. Lett. 104, 013109 (2014).

6. Wang, X. et al. Metal-enhanced hydrogenation of graphene with atomic pattern. Carbon 143, 700-705 (2019).

7. Hou, Y. et al. Insights into the isomeric effect on the self-assembly of donor-acceptor type aggregation-induced emission luminogens: Colour-tuning and shape-controlling. J. Lumin. 204, 221-229 (2018).

8. Wang, X., Wang, Z., Zhang, G. \& Jiang, J. Insight into Electronic and Structural Reorganizations for Defect-Induced $\mathrm{VO}_{2}$ Metal-Insulator Transition. J. Phys. Chem. Lett. 8, 3129-3132 (2017).

9. Liu, T., Zhou, X., Dupuis, M. \& Li, C. The nature of photogenerated charge separation among different crystal facets of $\mathrm{BiVO}_{4}$ studied by density functional theory. Phys. Chem. Chem. Phys. 17, 23503-23510 (2015).

10. Zhou., Z. et al. Probing electric field control of magnetism using ferromagnetic resonance. Nat. Commun. 6, 6082 (2015).

11. Zhang, Q. et al. Carbon nitride simultaneously boosted a PtRu electrocatalyst's stability and electrocatalytic activity toward concentrated methanol. Chem. Commun. 54, 9282-9285 (2018).

12. Zhang, J. et al. Porous polyaniline-derived $\mathrm{FeN}_{\mathrm{x}} \mathrm{C} / \mathrm{C}$ catalysts with high activity and stability towards oxygen reduction reaction using ferric chloride both as an oxidant and iron source. J. Mater. Chem. A 2, 1242-1246 (2014).

13. Bai, Y. et al. Controllably Interfacing with Metal: A Strategy for Enhancing CO Oxidation on Oxide Catalysts by Surface Polarization. J. Am. Chem. Soc. 136, 14650-14653 (2014).

14. Bao, H. et al. Crystal-Plane-Controlled Surface Restructuring and Catalytic Performance of Oxide Nanocrystals. Angew. Chem. Int. Ed. 50, 12294-12298 (2011).

15. Huang, T. J. \& Tsai, D. H. CO Oxidation Behavior of Copper and Copper Oxides. Catal. Lett. 87, 3-4 (2003).

16. Sun, S. et al. Low-temperature $\mathrm{CO}$ oxidation on $\mathrm{CuO} / \mathrm{CeO}_{2}$ catalysts: the significant effect of copper precursor and calcination temperature. Catal. Sci. Technol. 5, 3166-3181 (2015).

17. Duh, F. C. \& Lee, D. S. Au/CuO $-\mathrm{TiO}_{2}$ Catalysts for CO Oxidation at Low Temperature. Modern Research in Catalysis 2, 1-8 (2013).

18. Qi, C. et al. $\mathrm{CO}$ oxidation over gold catalysts supported on $\mathrm{CuO} / \mathrm{Cu}_{2} \mathrm{O}$ both in $\mathrm{O}_{2}$-rich and $\mathrm{H}_{2}$-rich streams: Necessity of copper oxide. Appl. Catal. B-Environ. 253, 160-169 (2019).

19. Kresse, G. \& Furthmüller, J. Efficient iterative schemes for ab initio total-energy calculations using a plane-wave basis set. Phys. Rev. B 54, 11169 (1996).

20. Blöchl, P. E. Projector augmented-wave method. Phys. Rev. B 50, 17953 (1994). 
21. Ernzerhof, M. \& Scuseria, G. E. Assessment of the Perdew-Burke-Ernzerhof exchange-correlation functional. J. Chem. Phys. 110, 5029-5036 (1999).

22. Tang, W., Sanville, E. \& Henkelman, G. A grid-based Bader analysis algorithm without lattice bias. J. Phys.-Condens. Mat. 21, 084204 (2009).

23. Henkelman, G., Uberuaga, B. P. \& Jónsson, H. A climbing image nudged elastic band method for finding saddle points and minimum energy paths. J. Chem. Phys. 113, 9901-9904 (2000).

24. Wadhwa, P., Liu, B., McCarthy, M. A., Wu, Z. \& Rinler, A. G. Electronic junction control in a nanotube-semiconductor Schottky junction solar cell. Nano Lett. 10, 5001-5005 (2010).

25. Freeouf, J. L. \& Woodall, J. M. Schottky barriers: An effective work function model. Appl. Phys. Lett. 39, 727-729 (1981).

26. Michaelides, A., Reuter, K. \& Scheffler, M. When seeing is not believing: Oxygen on Ag (111), a simple adsorption system? J. Vac. Sci. Technol. A 23, 1487-1497 (2005).

27. Wang, X. et al. Isolating hydrogen from oxygen in photocatalytic water splitting with a carbon-quantum-dot/carbon-nitride hybrid. J. Mater. Chem. A 7, 6143-6148 (2019).

28. Liu, B., Li, W., Song, W. \& Liu, J. Carbonate-mediated Mars-van Krevelen mechanism for CO oxidation on cobalt-doped ceria catalysts: facet-dependence and coordination-dependence. Phys. Chem. Chem. Phys. 20, 16045-16059 (2018).

29. Schlexer, P., Widmann, D., Behm, R. J. \& Pacchioni, G. C. O. Oxidation on a $\mathrm{Au} / \mathrm{TiO}_{2}$ Nanoparticle Catalyst via the Au-Assisted Mars-van Krevelen Mechanism. ACS. Catalysis 8, 6513 (2018).

30. Wu, L. N., Tian, Z. Y. \& Qin, W. DFT Study on CO Catalytic Oxidation Mechanism on the Defective $\mathrm{Cu}_{2} \mathrm{O}(111)$ Surface. J. Phys. Chem. C 122, 16733-16740 (2018).

31. Zhang, Z. et al. Site-Resolved $\mathrm{Cu}_{2} \mathrm{O}$ Catalysis in the Oxidation of CO. Angew. Chem. Int. Ed. 58, 4276-4280 (2019).

32. Nørskov, J. K. et al. Trends in the exchange current for hydrogen evolution. J. Electrochem. Soc. 152, 23-26 (2005).

33. Stamenkovic, V. et al. Changing the Activity of Electrocatalysts for Oxygen Reduction by Tuning the Surface Electronic Structure. Angew. Chem. Int. Ed. 45, 2897-2901 (2006).

\section{Acknowledgements}

This work was financially supported by the MOST (2018YFA0208603), the National Science Foundation of China (21633006, 21703224, 21703045), Anhui Initiative in Quantum Information Technologies (AHY090200). The numerical calculations in this paper have been done on the supercomputing system in the Supercomputing Center of University of Science and Technology of China and the National Supercomputing Center in Changsha.

\section{Author contributions}

X.L., J.J. and X.W. conceived the research and supervised the project. X.W. performed the simulations, X.W., C.J, E.S., G.Z., X.L. and J.J. analyzed the data, X.W., C.J., E.S., G.Z., X.L. and J.J. co-wrote the manuscript. All authors discussed the results and commented on the manuscript.

\section{Competing interests}

The authors declare no competing interests.

\section{Additional information}

Supplementary information is available for this paper at https://doi.org/10.1038/s41598-020-59531-0.

Correspondence and requests for materials should be addressed to X.L.

Reprints and permissions information is available at www.nature.com/reprints.

Publisher's note Springer Nature remains neutral with regard to jurisdictional claims in published maps and institutional affiliations.

(c) (i) Open Access This article is licensed under a Creative Commons Attribution 4.0 International License, which permits use, sharing, adaptation, distribution and reproduction in any medium or format, as long as you give appropriate credit to the original author(s) and the source, provide a link to the Creative Commons license, and indicate if changes were made. The images or other third party material in this article are included in the article's Creative Commons license, unless indicated otherwise in a credit line to the material. If material is not included in the article's Creative Commons license and your intended use is not permitted by statutory regulation or exceeds the permitted use, you will need to obtain permission directly from the copyright holder. To view a copy of this license, visit http://creativecommons.org/licenses/by/4.0/.

(c) The Author(s) 2020 